\title{
Evaluación de la fibroína de seda como biomaterial de soporte para el crecimiento de células mesenquimales estromales de pulpa dental
}

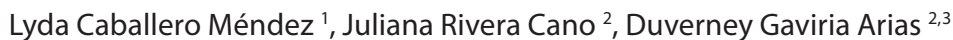

Resumen: La regeneración de tejidos usando células, factores de crecimiento y soportes constituyen una alternativa en la Medicina Regenerativa. La fibroína de seda es un excelente biosoporte, sus propiedades mecánicas únicas le permiten soportar procesos de adhesión y crecimiento celular. Objetivo. Evaluar la fibroína de la seda obtenida del gusano de seda Bombyx mori $L$ como material de soporte para el crecimiento de células mesenquimales estromales de pulpa dental (CMPD). Métodos. La fibroína obtenida a partir de capullos de gusanos de seda Bombyx mori L criados en la Granja El Pílamo, propiedad de la Universidad Tecnológica de Pereira, se empleó para la fabricación de películas de fibroína íntegras y resistentes a condiciones de cultivo. Las CMPD fueron obtenidas a partir de un donante de diente premolar, la pieza dental se cortó con disco de diamante para la obtención de la pulpa que fue sometida a disgregación enzimática. Las células obtenidas se subcultivaron hasta el segundo pase, para posteriormente transferirse a cajas de cultivo que contenían películas de fibroína, se sometieron a condiciones inherentes al proceso de incubación siguiendo su crecimiento y viabilidad celular durante 27 días. Resultados. Al final del periodo de incubación, se observaron películas integras, estables y resistentes que permitieron el crecimiento celular. Conclusión. Se plantea el uso de fibroína como un biopolímero natural que brinda un soporte mecánico, un microambiente óptimo y un mimetismo de la estructura organizacional de los tejidos, postulándose como un potencial biomaterial para procesos de crecimiento celular en Medicina Regenerativa e Ingeniería de Tejidos.

Palabras clave: Fibroína del gusano de seda; células estromales; biomateriales; Ingeniería de Tejidos; Medicina Regenerativa.

\begin{abstract}
Tissue regeneration using cells, growth factors and supports are an alternative in Regenerative Medicine. Silk fibroin is an excellent biosupport, its unique mechanical properties allow it to support processes of cell adhesion and growth. Objective: Evaluating the obtained silk's fibroin from silkworm (Bombyx mori L) as a scaffold material for growth of dental pulp mesenchymal stromal cells (CMPD). Methods: The fibroin was obtained from silkworm (Bombyx mori L) cocoons reared at "The Pilamo" Farm, owned by the Universidad Tecnológica de Pereira. Procedures for obtaining full and resistant fibroin films to culture conditions were performed. The CMPD were obtained from a premolar tooth, the tooth was cut with a diamond blade to obtain the pulp which was subjected to enzymatic digestion. The cells obtained were subcultured until the second pass, and then, transferred to culture dishes containing fibroin films. This cells were cultured in standard conditions and tracking incubation with cell viability and growth for 27 days. Results: At the end of the incubation period, we realize that the fibroin films were intact and also this fibroin films allows cell growth.Conclusion: The use of fibroin as a natural biopolymer provides mechanical support, also an optimal microenvironment and mimic the organizational structure of tissues, so we postulated fibroin as a potential biomaterial for cell growth to be used in regenerative medicine and tissue engineering.
\end{abstract}

Keywords: Silkworm fibroin; stromal cells; biomaterials; tissue engineering; regenerative medicine.

Fecha de envío: 6 de Febrero de 2016 - Fecha de aceptación: 31 de Mayo de 2016

\section{Introducción}

La ingeniería tisular y la medicina regenerativa surgen como las disciplinas que reúnen los conocimientos de la biología celular y las ciencias de la ingeniería aplicada a la formación de tejidos y órganos artificiales para uso clínico capaces de sustituir temporalmente las funciones perdidas de un tejido nativo y de órganos y/o ayudar a

(1) Facultad Ciencias de la Salud. Universidad Tecnológica de Pereira.

(2) Centro de Biología Molecular y Biotecnología, Facultad de Ciencias de la Salud, Universidad Tecnológica de Pereira.

(3) Universidad libre seccional Pereira.

Autor de Correspondencia: Iydaccm_27@utp.edu.co 
restaurar su plena capacidad. (Koh \& Atala, 2004; Kon'kov et al., 2010; Garrido, 2011). Uno de los aspectos claves en el área es el desarrollo de materiales que puedan interactuar con y dentro de sistemas biológicos, que sirvan como soporte mecánico, ayuden a regular actividades celulares y permitan la penetración y difusión de células, nutrientes, factores de crecimiento y desechos al igual que la unión entre células, y su diferenciación (Sobajo et al., 2008; Sangaj \& Varghese, 2011; Kundu, 2014; Sharma et al., 2014). Las propiedades intrínsecas del biomaterial (biocompatible, biodegradable, bioabsorbible) y la capacidad de apoyar la vascularización deben tenerse en cuenta como consideraciones importantes para la aplicación de estos biomateriales en la medicina regenerativa (Cao \& Wang, 2009; Wray et al., 2011; Sharma et al., 2014).

Los biomateriales usados como estromas biológicos se pueden clasificar en naturales o sintéticos, rígidos o no rígidos y degradables o no degradables. Los polímeros naturales son los biomateriales más ampliamente utilizados para la construcción de andamios por sus características diferenciales de composición, estructura y disposición de las macromoléculas constituyentes (Nair \& Laurencin, 2007; Sharma et al., 2014). Las proteínas que componen naturalmente los tejidos son una excelente elección para aplicaciones en la Ingeniería de Tejidos. Proteínas estructurales como colágeno, elastina, albúmina y fibrina son utilizadas actualmente como material de suturas, andamios de tejidos, agentes hemostáticos y para la administración de fármacos (Kundu et al., 2013). La fibroína del gusano de seda es un biopolímero natural con una larga historia de aplicaciones en el cuerpo humano como material de sutura y ligamentos artificiales; propiedades como su biocompatibilidad y biodegradabilidad le permiten ser actualmente utilizada para el desarrollo de gran variedad de dispositivos biomédicos y nuevas tecnologías de regeneración. (Sobajo et al., 2008; Sah \& Pramanik, 2010; Kundu, 2014; Zeng et al., 2014). La fibroína es el constituyente principal (72-81\%) de los capullos de gusano de seda Bombyx mori, (Sobajo et al., 2008; Cao \& Wang, 2009; Kon'kov et al., 2010; Sah \& Pramanik, 2010; Rockwood et al., 2011; Wray et al., 2011; Kundu, 2014; Zeng et al., 2014), es una glicoproteína hidrofóbica que contiene gran cantidad de enlaces de hidrógeno, su composición y orientación molecular permite la formación de una estructura semicristalina conformada por una fase cristalina altamente ordenada de hojas- $\beta$ antiparalelas que le confiere resistencia y tenacidad, separados por espaciadores de hoja- $\beta$ menos ordenados que contribuyen a la flexibilidad y elasticidad de la fibra. (Wang et al., 2006; Sah \& Pramanik, 2010; Wray et al., 2011; Kundu et al., 2014; Kundu, 2014).

Recientemente se ha demostrado que las matrices basadas en fibroína de la seda obtenidas a partir del gusano Bombyx mori presentan diversas morfologías, una tasa de degradación controlable y una buena biocompatibilidad. Debido a sus propiedades intrínsecas únicas y a su versatilidad, la seda es utilizada como un biomaterial para procesos biotecnológicos y de ingeniería de tejidos (Cao \& Wang, 2009; Kon'kov et al., 2010; Silva et al., 2013). El uso de los capullos requiere de un proceso de desgome con el fin de retirar la sericina, remanentes de esta proteína provocan reacciones inflamatorias, resistencia de la fibroína a la solubilización y alteración en la formación de la hoja- $\beta$ al establecer interacciones de tipo enlaces de hidrógeno. (Hardy \& Scheibel, 2010; Wray et al., 2011). El procesamiento de la seda requiere el uso de $\mathrm{Na}_{2} \mathrm{CO}_{3}$ (Rockwood et al., 2011; Deng et al., 2013; Kundu, 2014), seguido de un tratamiento con solventes iónicos como bromuro de litio ( $\mathrm{LiBr}$ ) o cloruro de calcio $\left(\mathrm{CaCl}_{2}\right.$ ) (Gellynck et al., 2008; Kharlampieva et al., 2010; George et al., 2013; YangáLiu et al., 2013; Kundu et al., 2014; Kundu, 2014). Sin embargo, en el momento de utilizar las películas de fibroína como material de soporte para el crecimiento de células se hace necesario inducir en su estructura la formación de hojas- $\beta$ que le confiere insolubilidad, incrementando su flexibilidad y su velocidad de degradación. Técnicas como el uso de solventes polares a diferentes concentraciones, estrés mecánico, tratamiento térmico y vapor de agua (water annealing) son utilizadas para la transición a esta estructura (Hu et al., 2007; Mo et al., 2009; Rockwood et al., 2011; Alleman et al., 2013; Zhu et al., 2014).

El uso de la fibroína como biomaterial acompañado de otros polímeros ha sido ampliamente utilizado con fines investigativos. Estudios recientes han utilizado soportes combinados de fibroína/ácido hialurónico para el cultivo de células madre mesenquimales, esta combinación favorece la respuesta de estímulos regenerativos de gran interés científico en la medicina regenerativa (Garcia-Fuentes et al., 2009). Otros estudios combinando biomateriales de fibroína/ quitosano han demostrado resultados exitosos y prometedores, como es el caso de Jiang Deng et ál., quienes utilizaron esta combinación de biomateriales junto con células madre mesenquimales de medula ósea en la reparación de lesiones en rodillas de conejos (Deng et al., 2013), o el estudio realizado por Yujun Wei et ál., quienes utilizaron esta combinación junto con células madre de tejido adiposo para el desarrollo de un injerto de nervio artificial que regeneró una lesión del nervio ciático inducida quirúrgicamente en modelo de rata (Wei et al., 2011). La fibroína como andamio se ha empleado recientemente para la reconstrucción de núcleo pulposo, mostrando ser un biomaterial poroso con propiedades mecánicas únicas, que proporciona un adecuado microambiente para apoyar el crecimiento de células de núcleo pulposo, la infiltración y secreción de matriz extracelular (Zeng et al., 2014). Recientemente se ha reportado el uso de microcápsulas de fibroína para la liberación controlada de fármacos y la utilización única o combinada de esta proteína con otros polímeros sintéticos como nanotubos de carbono, polietilenglicol, ácido poli- aspártico, ácido poliláctico y polímeros naturales como colágeno, quitosano, elastina, ácido hialurónico 
y queratina para la regeneración de diferentes tejidos. (Hardy \& Scheibel, 2010; Kon'kov et al., 2010; Kundu et al., 2013; Kundu et al., 2014). El uso de células madre son una alternativa promisoria para las aplicaciones en la terapia celular por su capacidad de auto renovación, proliferación y el potencial de diferenciación a diferentes linajes de células especializadas (Flores-Figueroa et al., 2006; Fabián et al., 2010). De acuerdo a International Society for Cellular Therapy, la denominación de célula madre mesenquimal es limitada a las células progenitoras multipotentes no hematopoyéticas aisladas y propagadas por clonaje in vitro, aptas para diferenciarse a los linajes celulares de osteoblastos, condrocitos y adipocitos y, capaces de expresar marcadores moleculares de superficie específicos (Dominici et al., 2006; Sanjurjo Rodríguez, 2012). En este contexto, el uso de células madre con fines terapéuticos también debe considerar su interacción con biomateriales que les permita alcanzar estabilidad intercelular y con la matriz extracelular bajo una arquitectura predeterminada (d'Aquino et al., 2008). Las células mesenquimales estromales de pulpa dental constituyen un excelente candidato para esta finalidad, son un tipo de células con capacidad adherente y potencial de diferenciación a varios linajes celulares incluyendo osteoblastos, odontoblastos, adipocitos y células neuronales (Kadar et al., 2009; Alleman et al., 2013). Estas células han demostrado interactividad con biomateriales para aplicaciones en la ingeniería de tejidos. (Flores-Figueroa et al., 2006; Fabián et al., 2010).

En este contexto, la fibroína de seda se ha utilizado ampliamente en la ingeniería de tejidos duros y blandos, sus diversas características entre las que se incluye su biocompatibilidad y la capacidad de apoyar la proliferación y diferenciación de diversos tipos celulares, lo hacen un atractivo candidato terapéutico en la terapia para enfermedades periodontales. Enfermedades cardiacas, diabetes y obesidad son las enfermedades típicas a nivel mundial, sin embargo, los pacientes con enfermedades dentales son muy superiores en número a los anteriormente descritos y son responsables de enormes costos para los proveedores de servicios médicos. La mayoría de los procedimientos dentales y maxilofaciales comprenden restauraciones de dientes simples a reconstrucción de los tejidos blandos y mineralizaciones faciales. En los Estados Unidos, las enfermedades periodontales afectan entre el 4-12\% de los adultos, una cuarta parte de esta población mayores de 65 años han perdido todos sus dientes (CDC 2011), casi todas las personas de edad avanzada han tenido los dientes artificiales o se han sometido a algún tipo de cirugía dental. Hasta la fecha, los materiales y las opciones de tratamiento disponibles tienen una capacidad limitada para reemplazar tejidos enfermos, infectados, traumatizados y/o perdidos. Varias estrategias de tratamiento están disponibles para los problemas dentales y la investigación en curso se centra en el desarrollo de nuevas terapias basadas en ingeniería de tejidos. El futuro potencial de la ingeniería dental es el uso de biomateriales como la fibroína de seda que favorezcan procesos de adhesión, crecimiento y diferenciación celular. (Kundu, 2014).

En este estudio, se empleó la fibroína de seda obtenida a partir de capullos del gusano de seda Bombyx mori como biosoporte para el crecimiento y multiplicación de células mesenquimales estromales de pulpa dental. El soporte se evaluó con base en su capacidad para mantener estable la viabilidad y el recuento celular en un periodo de tiempo.

\section{Metodología}

\section{Extracción de células}

Se adquirieron 2 premolares destinados a disposición final a partir de un único donante anónimo y con previa evaluación clínica realizada por un cirujano maxilofacial. El donante con 23 años de edad, de género masculino no presentaba problemas de pericoronitis, enfermedad periodontal o caries, y tenía indicación para extracción de los terceros molares de maxilar superior por ortodoncia. Las piezas dentales se obtuvieron por luxación previa verificación de que la historia clínica tuviese el consentimiento informado requerido para las exodoncias debidamente firmada y la valoración clínica negativa para cardiopatías, diabetes e hipertensión no controlada. De igual manera, el paciente aceptó su participación en dicho estudio a través de un consentimiento informado que establece la donación de la pieza dental y su uso solo con fines investigativos. Con el fin de disminuir la carga bacteriana el paciente realizó un colutorio con clorhexidina al $2 \%$ durante 2 minutos, se anestesió usando lidocaína al $2 \%$ con epinefrina mediante la técnica infiltrativa, inyectando el anestésico vía vestibular con refuerzo palatino y permitiendo el inicio del efecto anestésico durante un periodo de 10 minutos. Finalmente, la extracción de las piezas dentales se realizó con ayuda de un fórceps 150 . El procedimiento descrito fue revisado y aprobado por el comité de bioética de la Facultad de Ciencias de la Salud de la Universidad Tecnológica de Pereira.

Las piezas dentales se lavaron mediante inmersiones seriadas en buffer fosfato salino $\sin \mathrm{Ca}^{++}$ni $\mathrm{Mg}^{++}$(PBSA), solución desinfectante de yodopovidona $10 \%$ (Isodine ${ }^{\circledR}$, Boehringer Ingelheim) y solución salina 0,85\% con tiempos de inmersión de 3-5 minutos en cada solución, y después se mantuvieron en un recipiente plástico con PBSA frío contenido en un baño de hielo. Con un disco de diamante, en pieza de baja e irrigación con PBSA estéril, se partió cada molar mediante corte transversal seguido de corte longitudinal hasta lograr la extracción completa de la pulpa dental con ayuda de una excavadora dental. Cada corte iba seguido de baños intermitentes del molar en el DPBS contenido en baño de agua con hielo. Todas las soluciones trabajadas estaban estériles. Las pulpas dentales recuperadas se mantuvieron en medio de cultivo DMEM completo 
(Dulbecco's Modified Eagle suplementado con suero fetal bovino $10 \%$, glutamina $1 \%$, penicilina-estreptomicina $1 \%$ y anfotericina $B$ $0,1 \%)$ y refrigerado durante 28 horas entre 2 y $4^{\circ} \mathrm{C}$.

\section{Multiplicación de células}

La pulpa dental fue fraccionada en pequeños trozos con ayuda de un bisturí estéril. Después se sometió a digestión enzimática con una solución 1:1 de dispasa $(2 \mathrm{mg} / \mathrm{mL}) /$ colagenasa tipo I $(4 \mathrm{mg} / \mathrm{mL})$ durante 50 minutos a $37^{\circ} \mathrm{C}$. Pasado este tiempo, el proceso de digestión se detuvo mediante dilución con 5 volúmenes de medio de cultivo DMEM completo; la solución se centrifugó a 500xg por 6 minutos con descarte del sobrenadante y resuspensión del botón celular en $3 \mathrm{~mL}$ de medio DMEM completo. La suspensión celular se sembró en 3 placas T25, utilizando $1 \mathrm{~mL}$ de la suspensión con $5 \mathrm{~mL}$ de medio de cultivo DMEM completo por cada placa, para después mantenerlas en incubación a $37^{\circ} \mathrm{C}, 5 \% \mathrm{CO}_{2}$ y $90 \%$ de humedad durante 7 días. Finalizados los 7 días de incubación, se retiró el medio de cultivo de cada placa T25 y se vertió medio de cultivo DMEM completo nuevo para evitar inanición celular por carencia de nutrientes y descenso del pH del medio producto del metabolismo celular. El recambio de medio se realizó cada 2 días por un periodo de 12 días.

\section{Criopreservación}

Las células procedentes de las cajas T25 de los cultivos primarios, se desprendieron con solución de tripsina 0,5\% en EDTA $1 \mathrm{mM}$ seguida de su inactivación con medio de cultivo DMEM completo, de acuerdo con el procedimiento antes descrito hasta la resuspensión del botón celular en $800 \mu \mathrm{L}$ de suero fetal bovino (SFB), a la suspensión celular se le adicionaron $200 \mu \mathrm{L}$ de dimetil sulfóxido (Calbiochem CAT No 317275), se transfirieron a viales de criopreservación, se mantuvieron a $-80^{\circ} \mathrm{C}$ durante 24 horas y después se trasladaron a fase de vapor de nitrógeno líquido en un tanque de criopreservación para su conservación prolongada a $-196^{\circ} \mathrm{C}$.

\section{Preparación fibroína}

Los capullos fueron obtenidos a partir de gusanos de seda B. mori criados en la granja experimental "El Pilamo"/ Universidad Tecnológica de Pereira, Pereira / Risaralda, estos capullos se limpiaron manualmente para retirar restos de crisálida, segmentos con manchas o sectores defectuosos. Los capullos se cortaron a la mitad para su ebullición en $\mathrm{Na}_{2} \mathrm{CO}_{3} 0,02 \mathrm{M}$ durante 1 hora con el fin de desgomar la fibroína: $5 \mathrm{~g}$ de capullos por cada litro de la solución. La fibroína desgomada resultante se lavó con agua destilada y se dejó secando en horno a $60^{\circ} \mathrm{C}$ por 6 horas. La disolución de la fibroína se logró mediante la incubación en baño maría a $60^{\circ} \mathrm{C} / 4$ horas en una solución de $\mathrm{LiBr}$ 9,3M y $10 \%$ de fibroína desgomada (p/v). La fibroína disuelta y centrifugada se dializó en tubos de membrana de diálisis con MWCO 6-8000, durante 3 días contra agua destilada con recambios cada 2 horas para el primer día, cada 4 horas para el segundo día y, cada 6 horas para el tercer día. Finalmente, la solución obtenida se contradializó (Av. Mol Wt 8000) con una solución de polietilenglicol al 30\% hasta conseguir una concentración de fibroína al 17\% en agitación continua.

\section{Construcción de soportes}

La solución de fibroína al $17 \%$ se dispuso en cajas de poliestireno P-35mm para cultivo celular y se secaron mediante exposición en cabina de flujo laminar por 72 horas. Finalizado el periodo de secado, las películas de fibroína formadas se sometieron a water-annealing durante 4 horas y $25 \mathrm{inHg}$ para inducir la formación de hojas- $\beta$ y estabilizar el soporte. Posteriormente, se esterilizaron con etanol al 70\% por media hora y se lavaron con PBSA estéril para eliminar los residuos de alcohol, quedando listas para su uso.

\section{Crecimiento en soportes}

Para realizar los ensayos con CMPD, un criovial que contenía 1 x $10^{6} \mathrm{Cel} / \mathrm{mL}$ se llevó a baño de agua estéril mantenida a $37^{\circ} \mathrm{C}$ durante 1 minuto para descongelar su contenido, se descontaminó su superficie externa mediante aspersión con etanol al 70\%; el contenido se trasladó a un tubo que contenía $9 \mathrm{~mL}$ de DMEM completo, se centrifugó 500xg por 6 minutos y se eliminó el sobrenadante. El botón celular remanente se resuspendió en $1 \mathrm{~mL}$ de medio de cultivo DMEM completo, y se determinó la viabilidad de la suspensión celular resultante por ensayo de exclusión con azul de tripano para después sembrarla con $5 \mathrm{~mL}$ de medio de cultivo DMEM completo en un frasco T25. El recambio de medio de cultivo, la expansión y los subcultivos celulares se realizaron de la forma previamente descrita. A partir del segundo subcultivo, se sembraron $5000 \mathrm{cel} / \mathrm{cm}^{2}$ sobre cada caja P-35mm que contenían películas de fibroína listas para su uso, a su vez se sembró la misma población de células (células mesenquimales estromales de pulpa dental) sobre dos cajas de poliestireno sin película de fibroína usadas como control positivo con el fin de comparar el crecimiento y la morfología celular. Se realizaron cambios de medio cada dos días utilizando DMEM completo.

\section{Estabilidad de soportes}

Para evaluar la estabilidad de la película a la inmersión en medio de cultivo se tomó una caja que contenía una película de fibroína, se esterilizó con etanol al 70\%, se lavó con PBSA estéril y se incubó con $2 \mathrm{~mL}$ de DMEM completo por un periodo de 153 días con el fin de evaluar la estabilidad de la estructura en contacto permanente con el medio de cultivo.

\section{Viabilidad, multiplicación}

Las películas fueron acondicionadas con $2 \mathrm{~mL}$ de DMEM completo por tres días antes de su uso con el fin de evaluar su estabilidad frente a condiciones propias del proceso de incubación; en cada caja se sembró una densidad de $5000 \mathrm{cel} / \mathrm{cm}^{2}$, cada dos días se realizó cambio del medio DMEM. En los días 5, 11, 18 y 27, cuando las células alcanzaron una confluencia cercana al $80 \%$, fueron desprendidas de las películas de fibroína utilizando tripsina-EDTA al $0.5 \%$. El remanente 
de células que quedaba después de la tripsinización continuaba su proceso de incubación con $2 \mathrm{~mL}$ de DMEM hasta obtener una confluencia cercana al $80 \%$ para repetir el proceso de disgregación celular en los días anteriormente mencionados a partir de momento de incubación con el fin de evaluar la capacidad de las células para multiplicarse y conocer su comportamiento sobre este soporte. Se realizó recuento de células/mL y porcentaje de viabilidad celular utilizando el ensayo de exclusión con azul de tripano en cámara de Neubauer posterior al tratamiento con tripsina. Después de cada proceso de disgregación enzimática, las células desprendidas se sembraron en cajas de cultivo T25 para continuar su proceso de incubación con recambios de medio cada 2 días hasta alcanzar confluencia cercana al $80 \%$, equivalente a un número de células por $\mathrm{cm}^{2}$ suficientes para llevar a cabo el proceso de congelamiento a $-196^{\circ} \mathrm{C}$ en nitrógeno líquido. Todos los recambios de medio de cultivo se monitorearon mediante cultivo de gérmenes comunes con el fin de verificar la esterilidad durante el periodo de experimentación.

\section{Análisis estadístico}

Los datos obtenidos a partir de los recuentos celulares y los porcentajes de viabilidad de las células sembradas sobre las películas de fibroína y sobre el control positivo, se analizaron mediante un T-Test de dos colas, con un intervalo de confianza del 99\% $\mathrm{P}<0,01$, con el fin de determinar significancia estadística.

\section{Resultados}

\section{Preparación fibroína}

El tratamiento de desengome de los capullos permitió identificar la relación existente entre sericina y fibroína, identificándose que en peso la sericina corresponde al $30 \%$ del capullo. A partir de los capullos del gusano de seda desengomados se obtuvo una solución al 10\% de fibroína de seda en $\mathrm{LiBr}$ 9,3M, la solución obtenida se centrifugó y se filtró para eliminar restos de crisálida. Finalmente, un proceso de diálisis utilizando membranas de celulosa, seguido de contra diálisis con PEG permitieron obtener una solución acuosa de fibroína mantenida a $4^{\circ} \mathrm{C}$ hasta su posterior uso. (Figura 1).

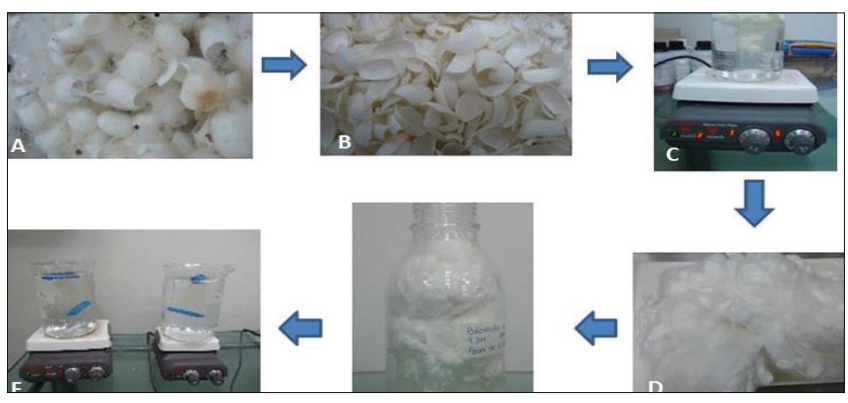

Figura 1: Procesamiento de la fibroína.

A: Capullos de gusano de seda. B: Capullos limpios partidos a la mitad.

C: Ebullición de capullos en Na2CO3 0,0M. D: Fibroína desgomada.

E: Fibroína disuelta en $\mathrm{LiBr}$ 9,3M. F: Fibroína en proceso de diálisis.

\section{Construcción de soportes}

El tratamiento de water annealing permitió obtener películas integras, de superficie lisa, resistentes a la manipulación, adheridas completamente a la superficie de la caja de poliestireno. (Figura 2).

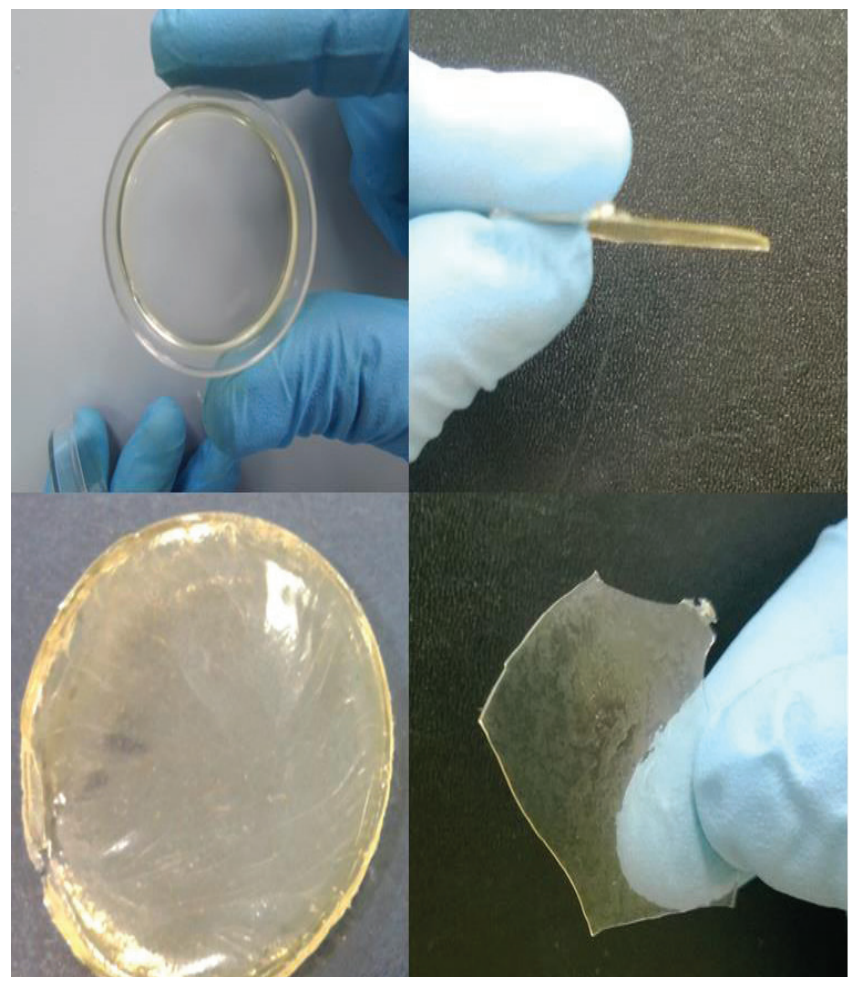

Figura 2: Película de fibroína de seda obtenida por water annealing

Las células sembradas sobre las películas de fibroína estéril alimentadas cada dos días se comportaron de manera similar al control positivo (Figura 3). Se observaron células fusiformes adheridas a la superficie de la película con presencia de colonias celulares en los primeros días de incubación. La morfología de las células sembradas sobre las películas de fibroína durante todo el proceso de incubación fue similar al control positivo. Las células que alcanzaron una confluencia cercana al $80 \%$ fueron desprendidas en los días $5^{\circ}, 11^{\circ}, 18^{\circ}$ y $27^{\circ}$, las películas de fibroína junto con el remanente de células se reincubaron con $2 \mathrm{~mL}$ de DMEM completo hasta obtener una confluencia cercana al 80\%, para realizar de nuevo el proceso de disgregación celular con tripsina al $0.5 \%$. Las células obtenidas del proceso de disgregación se congelaron a $-196^{\circ} \mathrm{C}$ en nitrógeno líquido. Cada recambio de medio de cultivo fue monitoreado mediante el análisis de gérmenes comunes para verificar su esterilidad con resultados dentro de la especificación para todos los monitoreos: $<1 \mathrm{UFC} / 100 \mu \mathrm{L}$ a los 7 días de incubación. 


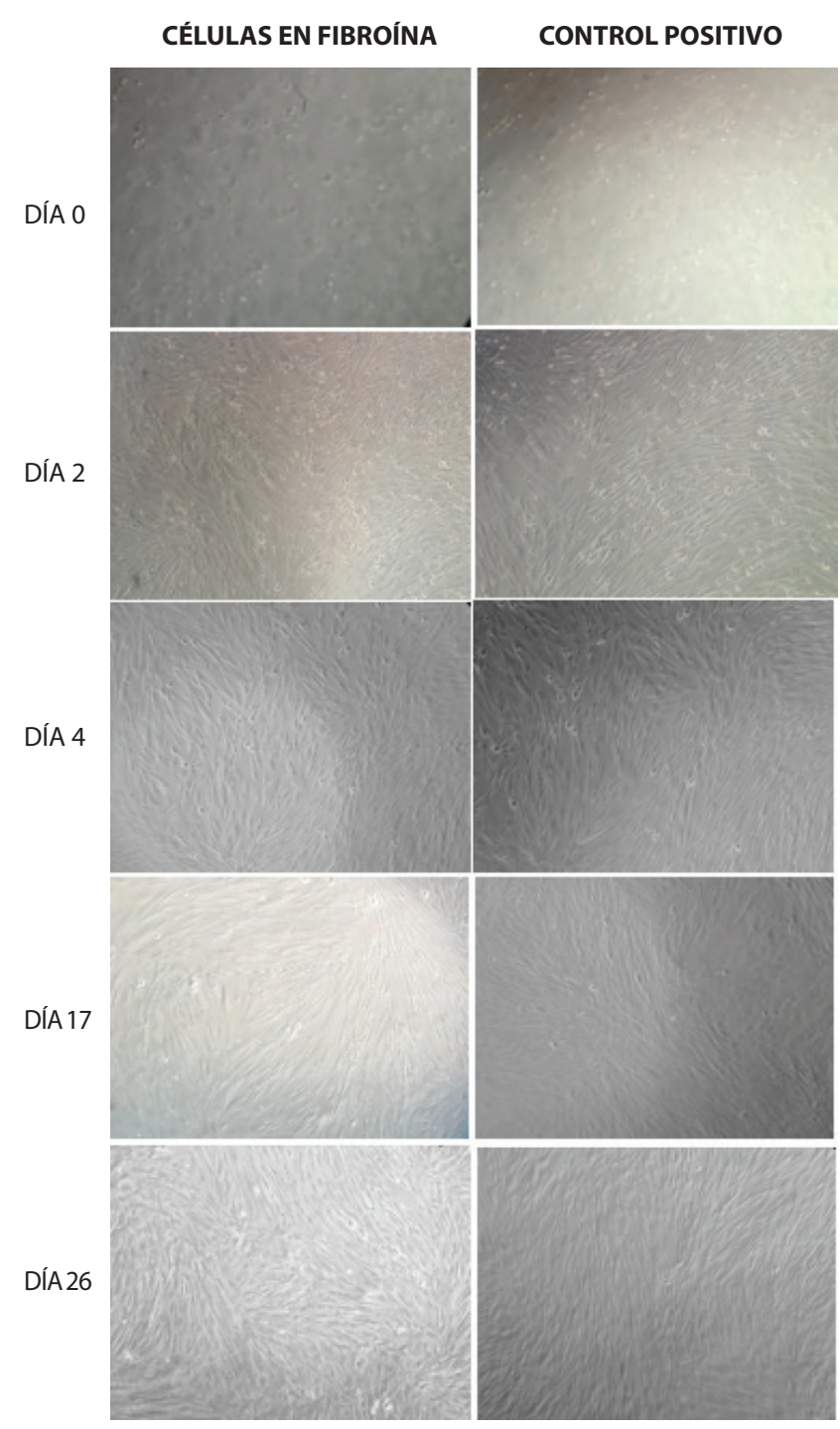

Figura 3: Crecimiento de células estromales sobre películas de fibroína. Izquierda: crecimiento de células mesenquimales estromales de pulpa dental sobre películas de fibroína. Derecha: células mesenquimales estromales de pulpa dental sobre cajas de poliestireno. Microscopio invertido 10x.

\section{Estabilidad de los soportes}

La película de fibroína incubada con DMEM completo por 5 meses no evidenció signos de fractura, pérdida de integridad ni disolución. (Figura 4).
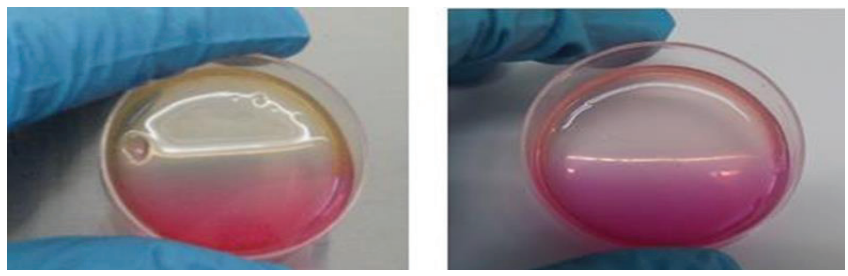

Figura 4: Película de fibroína Izquierda: película de fibroína con DMEM a los tres meses. Derecha: película de fibroína con DMEM a los cinco meses.

\section{Viabilidad, multiplicación}

El recuento de células/mL y el porcentaje de viabilidad celular realizado a las dos cajas de fibroína y a los controles positivos se mantuvo estable en cada proceso de tripsinización. El remanente de células demostró capacidad de multiplicación sobre las películas de fibroína alcanzando confluencias entre el 80-90\%, sin afectar la viabilidad celular. Las películas no evidenciaron signos de fracturas, disolución, ni pérdida de la integridad. (Figura 5)

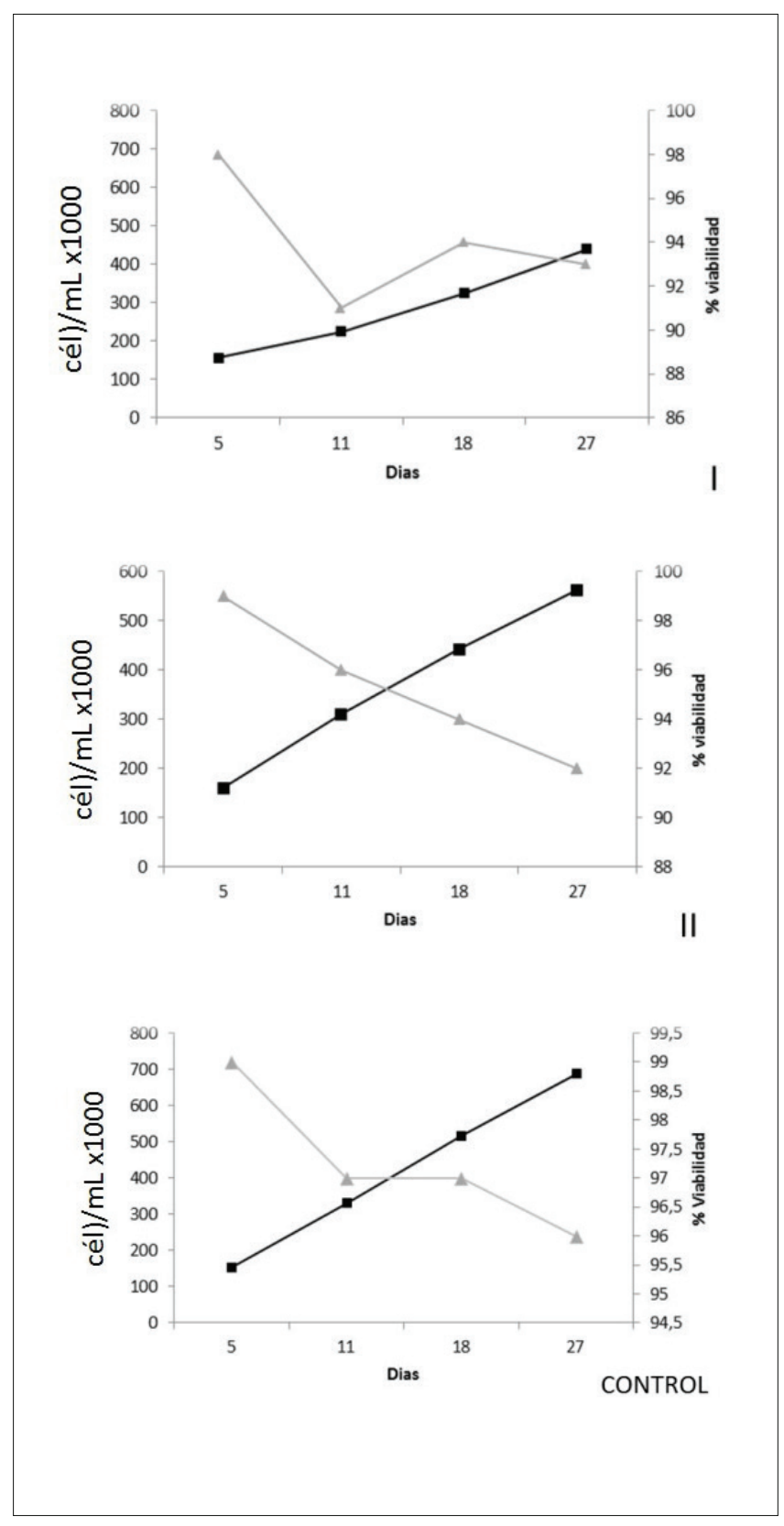

Figura 5: Recuento de cél/ $\mathrm{mL}$ y viabilidad celular de las CMPD sembradas sobre películas de fibroína y el control positivo. I y II cajas de fibroína y CMPD. Línea gris con triángulo: porcentaje de viabilidad celular, línea negra con cuadrado: recuento acumulado de cél/mL. 


\section{Análisis estadístico}

Los porcentajes de viabilidad de las células sembradas sobre las cajas I y II y los controles positivos no muestran diferencias significativas, lo que permite concluir que la viabilidad de las células no se ve afectada por el soporte de fibroína (Figura 6). No hubo diferencias significativas entre los datos de concentración celular obtenidos en el ensayo y el control. (Figura 6)

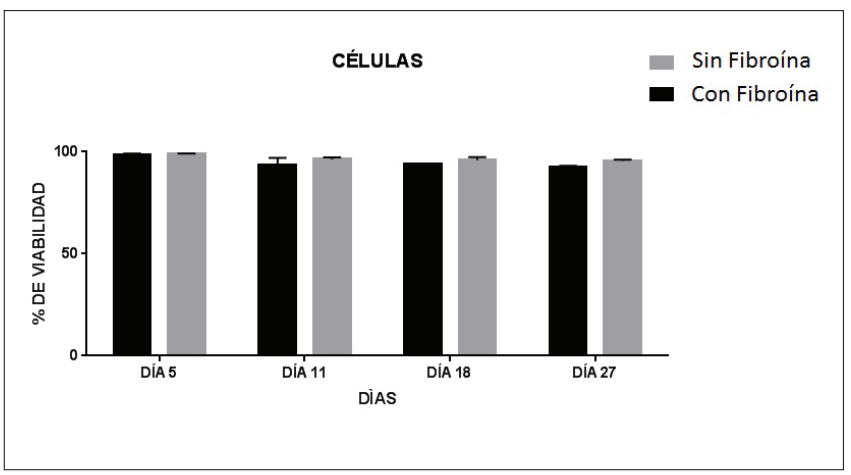

Figura 6: Viabilidad celular con y sin películas de fibroína. Porcentaje de viabilidad celular de las muestras y el control positivo durante todo el ensayo.

\section{Discusión y conclusiones}

Los biomateriales desempeñan un papel crucial en el campo de la ingeniería de tejidos y la medicina regenerativa ya que constituyen una excelente fuente para la fabricación de estromas que presentan poros interconectados para establecer un óptimo microambiente celular requerido para la regeneración de un tejido (Sharma et al., 2014). Se estableció un protocolo para la obtención de matrices de fibroína a partir de capullos del gusano de seda aptas para el cultivo celular in vitro. El protocolo aquí descrito surge de la estandarización de técnicas citadas por otros autores con modificaciones puntuales del proceso. La fase inicial en la fabricación de estructuras basadas en fibroína consiste en una estricta selección del material, el empleo de capullos con restos de crisálida, segmentos con manchas o zonas defectuosas puede afectar considerablemente la calidad de la película. El uso de $\mathrm{Na}_{2} \mathrm{CO}_{3}$ al 0,02M permitió obtener fibroína libre de sericina demostrando así que el desgome es una actividad clave del proceso para obtención de la fibroína en fase acuosa y es efectivo si se utiliza una sal en condiciones estandarizadas de temperatura y tiempo como lo sugiere Kundu en su libro. "Silk Biomaterials for tissue engineering and regenerative medicine" (Kundu, 2014). El tratamiento con $\mathrm{LiBr}$ 9,3M disuelve completamente la fibroína hasta obtener una solución homogénea, que puede ser utilizada para la fabricación de películas, esponjas, fibras, geles u otro tipo de estructura. Varios estudios reportan el uso de soluciones de fibroína con valores desconocidos de concentración, este aspecto puede afectar considerablemente la integridad de la película, ya que soluciones muy diluidas de proteína obtenidas a partir de los procesos de diálisis no permiten obtener estructuras estables; en este estudio se demostró la eficiencia del polietilenglicol para concentrar la fibroína a valores deseados sin afectar la estructura de la proteína, permitiendo así el uso de esta solución dentro del proceso de elaboración de películas u otro tipo de estructuras para el cultivo de células in vitro.

La técnica water annealing empleada para inducir la cristalización de las películas resultó ser exitosa, ya que se obtuvieron estructuras resistentes, íntegras, estables al medio de cultivo y a condiciones propias del proceso de incubación, sin embargo, este proceso puede provocar la ruptura de la película cuando se expone por un tiempo mayor al sugerido. Otros estudios demuestran resultados favorables utilizando solventes polares a diferentes concentraciones para inducir la cristalización de la estructura (Garcia-Fuentes et al., 2009; Zeng et al., 2014).

El método de esterilización con etanol al 70\% demostró ser efectivo para las películas usadas en el cultivo in vitro de CMPD, ya que el medio DMEM obtenido de los recambios resultaron negativos para el cultivo de gérmenes comunes a los 7 días de incubación. Otros métodos de esterilización apropiados resultan de la exposición de las películas a óxido de etileno, radiación gamma y autoclavado. Las películas de fibroína que contenían las CMPD soportaron 27 días de incubación con medio DMEM a $35^{\circ} \mathrm{C}, 5 \% \mathrm{CO}_{2}$ y atmósfera húmeda por un periodo continuo, sin mostrar signos de deterioro, fractura o disolución. La película de fibroína incubada por 5 meses con DMEM no evidenció signos de desgaste ni lavado con el medio. El proceso de tripsinización usado para desprender las células del soporte de fibroína no afectó la integridad de las películas. Por tanto, la resistencia de esta estructura en condiciones inherentes al proceso de incubación, cambios de medio de cultivo y disgregación celular postulan el uso de la fibroína de seda como un potente biomaterial que puede ser ampliamente utilizado en la medicina regenerativa y la ingeniería de tejidos. Estas características en un biomaterial son importantes en aquellos casos en los que se requiere un tiempo prolongado para el establecimiento del implante. El análisis estadístico demostró que el soporte de fibroína de seda no afecta la viabilidad ni la concentración celular in vitro. Todo lo anterior demuestra la capacidad de la fibroína de seda para soportar el crecimiento celular.

Se demostró la capacidad de la fibroína de seda para soportar la adherencia, crecimiento y multiplicación de células mesenquimales estromales obtenidas de cultivo primario de pulpa dental. Se identificó que la técnica de cristalización por water annealing es una técnica adecuada, que permite que la película de fibroína mantenga sus propiedades mecánicas en condiciones de cultivo celular y tratamiento con proteasas como la tripsina. 
Este andamio se caracteriza por sus propiedades mecánicas únicas, su tasa de degradación y su biocompatibilidad. Los resultados experimentales in vitro demostraron que este soporte no afecta la viabilidad, concentración y morfología celular, por tanto, este biomaterial podría proporcionar un microambiente adecuado para apoyar el crecimiento de células madre en un modelo in vivo, sin embargo, se recomienda realizar una caracterización mecánica, biológica y molecular del soporte de fibroína seda que demuestre que esta proteína permite favorecer procesos de diferenciación de diversas poblaciones celulares incluyendo células mesenquimales estromales de pulpa dental hacia fenotipos odontoblásticos orientados a la regeneración dentino-pulpar. Por tanto, se sugiere realizar nuevos ensayos con diferentes tipos de poblaciones celulares y variaciones en la estructura física del biomaterial que permitan corroborar el uso de fibroína como material de soporte útil en la regeneración de tejidos y reparación de órganos. Finalmente, este estudio permite sugerir la fibroína como biomaterial capaz de soportar el crecimiento celular así como condiciones inherentes al proceso de incubación in vitro, concluyendo que la que aplicación de soportes basados en fibroína de seda son un modelo factible en la ingeniería de tejidos.

\section{Contribuciones y reconocimientos}

El desarrollo experimental de la investigación fue realizada por las estudiantes adscritas al programa de posgrado en Msc. Biología molecular, la supervisión fue realizada por el Dr. Duverney Gaviria, quien a su vez apoyó los procesos de análisis de resultados y escritura final del documento. Los autores declaran no tener conflictos de intereses, y aseguran que los recursos utilizados para el desarrollo del estudio fueron suministrados por el Centro de Biología Molecular y Biotecnología adscrito a la Facultad de Ciencias de la Salud de la Universidad Tecnológica de Pereira.

\section{Referencias}

Alleman M, Low E, Truong K, Huang E, Hill C, Chen T, Deaton M \& Kingsley K. (2013). Dental pulp-derived stem cells (DPSC) differentiation in vitro into odontoblast and neuronal progenitors during cell passaging is associated with alterations in cell survival and viability. International Journal of Medicine and Biomedical Research 2, 133-141.

Cao Y \& Wang B. (2009). Biodegradation of silk biomaterials. International journal of molecular sciences 10, 1514-1524.

d'Aquino R, Papaccio G, Laino G \& Graziano A. (2008). Dental pulp stem cells: a promising tool for bone regeneration. Stem cell reviews 4, 21-26.
Deng J, She R, Huang W, Dong Z, Mo G \& Liu B. (2013). A silk fibroin/ chitosan scaffold in combination with bone marrow-derived mesenchymal stem cells to repair cartilage defects in the rabbit knee. Journal of Materials Science: Materials in Medicine 24, 2037-2046.

Dominici M, Le Blanc K, Mueller I, Slaper-Cortenbach I, Marini F, Krause D, Deans R, Keating A, Prockop D \& Horwitz E. (2006). Minimal criteria for defining multipotent mesenchymal stromal cells. The International Society for Cellular Therapy position statement. Cytotherapy 8, 315-317.

Fabián MM, Rodríguez BC \& Pérezll MAÁ. (2010). Aislamiento y caracterización parcial de células madre de pulpa dental. Revista Odontológica Mexicana 14, 15-20.

Flores-Figueroa E, Montesinos JJ \& Mayani H. (2006). Células troncales mesenquimales: historia, biología y aplicación clínica. Revista de investigación clínica 58, 498-511.

Garcia-Fuentes M, Meinel AJ, Hilbe M, Meinel L \& Merkle HP. (2009). Silk fibroin/hyaluronan scaffolds for human mesenchymal stem cell culture in tissue engineering. Biomaterials 30, 5068-5076.

Garrido M. (2011). Ingeniería tisular y medicina regenerativa en cirugía pediátrica. Revista chilena de cirugía 63, 635-640.

Gellynck K, Verdonk PC, Van Nimmen E, Almqvist KF, Gheysens T, Schoukens G, Van Langenhove L, Kiekens P, Mertens J \& Verbruggen G. (2008). Silkworm and spider silk scaffolds for chondrocyte support. Journal of Materials Science: Materials in Medicine 19, 3399-3409.

George KA, Shadforth A, Chirila TV, Laurent MJ, Stephenson S-A, Edwards GA, Madden PW, Hutmacher DW \& Harkin DG. (2013). Effect of the sterilization method on the properties of Bombyx mori silk fibroin films. Materials Science and Engineering: C 33, 668-674.

Hardy JG \& Scheibel TR. (2010). Composite materials based on silk proteins. Progress in Polymer Science 35, 1093-1115.

Hu X, Kaplan D \& Cebe P. (2007). Effect of water on the thermal properties of silk fibroin. Thermochimica Acta 461, 137-144.

Kadar K, Kiraly M, Porcsalmy B, Molnar B, Racz G, Blazsek J, Kallo K, Szabo E, Gera I \& Gerber G. (2009). Differentiation potential of stem cells from human dental origin-promise for tissue engineering. $J$ Physiol Pharmacol 60, 167-175.

Kharlampieva E, Kozlovskaya V, Wallet B, Shevchenko VV, Naik RR, Vaia R, Kaplan DL \& Tsukruk VV. (2010). Co-cross-linking silk matrices with silica nanostructures for robust ultrathin nanocomposites. ACS nano 4, 7053-7063. 
Koh CJ \& Atala A. (2004). Tissue engineering, stem cells, and cloning: opportunities for regenerative medicine. Journal of the American Society of Nephrology 15, 1113-1125.

Kon'kov A, Pustovalova O \& Agapov I. (2010). Biocompatible materials from regenerated silk for tissue engineering and medicinal therapy. Applied biochemistry and microbiology 46, 739-744.

Kundu B, Kurland NE, Bano S, Patra C, Engel FB, Yadavalli VK \& Kundu SC. (2014). Silk proteins for biomedical applications: bioengineering perspectives. Progress in Polymer Science 39, 251-267.

Kundu B, Rajkhowa R, Kundu SC \& Wang X. (2013). Silk fibroin biomaterials for tissue regenerations. Advanced drug delivery reviews $65,457-470$.

Kundu S. (2014). Silk Biomaterials for Tissue Engineering and Regenerative Medicine. Elsevier.

Mo C, Wu P, Chen X \& Shao Z. (2009). The effect of water on the conformation transition of Bombyx mori silk fibroin. Vibrational Spectroscopy 51, 105-109.

Nair LS \& Laurencin CT. (2007). Biodegradable polymers as biomaterials. Progress in polymer science 32, 762-798.

Rockwood DN, Preda RC, Yücel T, Wang X, Lovett ML \& Kaplan DL. (2011). Materials fabrication from Bombyx mori silk fibroin. Nature protocols 6, 1612-1631.

Sah M \& Pramanik K. (2010). Regenerated silk fibroin from B. mori silk cocoon for tissue engineering applications. Int J Environ Sci Technol 1, 404-408.

Sangaj N \& Varghese S. (2011). Controlling Stem Cells with Biomaterials. Springer.

Sanjurjo Rodríguez C. (2012). Diferenciación" in vitro" de células madre aisladas de médula ósea humana sobre biomateriales de colágeno.
Sharma S, Srivastava D, Grover S \& Sharma V. (2014). Biomaterials in Tooth Tissue Engineering: A Review. Journal of clinical and diagnostic research: JCDR 8, 309.

Silva SS, Popa EG, Gomes ME, Oliveira MB, Nayak S, Subia B, Mano JF, Kundu SC \& Reis RL. (2013). Silk hydrogels from non-mulberry and mulberry silkworm cocoons processed with ionic liquids. Acta biomaterialia 9, 8972-8982.

Sobajo C, Behzad F, Yuan X-F \& Bayat A. (2008). Silk: a potential medium for tissue engineering. Eplasty 8.

Wang Y, Kim H-J, Vunjak-Novakovic G \& Kaplan DL. (2006). Stem cell-based tissue engineering with silk biomaterials. Biomaterials 27, 6064-6082.

Wei Y, Gong K, Zheng Z, Wang A, Ao Q, Gong Y \& Zhang X. (2011). Chitosan/silk fibroin-based tissue-engineered graft seeded with adipose-derived stem cells enhances nerve regeneration in a rat model. Journal of Materials Science: Materials in Medicine 22, 1947-1964.

Wray LS, Hu X, Gallego J, Georgakoudi I, Omenetto FG, Schmidt D \& Kaplan DL. (2011). Effect of processing on silk-based biomaterials: Reproducibility and biocompatibility. Journal of Biomedical Materials Research Part B: Applied Biomaterials 99, 89-101.

YangáLiu X, JináChuah Y, James C \& LiangáLi J. (2013). Design and engineering of silk fibroin scaffolds with biomimetic hierarchical structures. Chemical Communications 49, 1431-1433.

Zeng C, Yang Q, Zhu M, Du L, Zhang J, Ma X, Xu B \& Wang L. (2014). Silk fibroin porous scaffolds for nucleus pulposus tissue engineering. Materials Science and Engineering: C 37, 232-240.

Zhu M, Wang K, Mei J, Li C, Zhang J, Zheng W, An D, Xiao N, Zhao Q \& Kong D. (2014). Fabrication of highly interconnected porous silk fibroin scaffolds for potential use as vascular grafts. Acta biomaterialia 10. 